\title{
Vitamin D status of Irish adults: findings from the National Adult Nutrition Survey
}

\author{
Kevin D. Cashman ${ }^{1,2 *}$, Siobhan Muldowney ${ }^{1}$, Breige McNulty ${ }^{3}$, Anne Nugent ${ }^{3}$, Anthony P. FitzGerald ${ }^{4,5}$, \\ Mairead Kiely ${ }^{1}$, Janette Walton ${ }^{1}$, Michael J. Gibney ${ }^{3}$ and Albert Flynn ${ }^{1}$ \\ ${ }^{1}$ School of Food and Nutritional Sciences, University College Cork, Cork, Republic of Ireland \\ ${ }^{2}$ Department of Medicine, University College Cork, Cork, Republic of Ireland \\ ${ }^{3}$ UCD Institute of Food and Health, University College Dublin, Dublin, Republic of Ireland \\ ${ }^{4}$ Department of Epidemiology and Public Health, University College Cork, Cork, Republic of Ireland \\ ${ }^{5}$ Department of Statistics, University College Cork, Cork, Republic of Ireland
}

(Submitted 25 January 2012 - Final revision received 31 May 2012 - Accepted 3 June 2012 - First published online 10 August 2012)

\begin{abstract}
Previous national nutrition surveys in Irish adults did not include blood samples; thus, representative serum 25-hydroxyvitamin D (25(OH)D) data are lacking. In the present study, we characterised serum $25(\mathrm{OH}) \mathrm{D}$ concentrations in Irish adults from the recent National Adult Nutrition Survey, and determined the impact of vitamin D supplement use and season on serum $25(\mathrm{OH}) \mathrm{D}$ concentrations. Of the total representative sample ( $n$ 1500, aged $18+$ years), blood samples were available for 1132 adults. Serum 25(OH)D was measured via immunoassay. Vitamin Dcontaining supplement use was assessed by questionnaire and food diary. Concentrations of serum 25(OH)D were compared by season and in supplement users and non-users. Year-round prevalence rates for serum $25(\mathrm{OH}) \mathrm{D}$ concentration $<30,<40,<50$ and $<75 \mathrm{nmol} / \mathrm{l}$ were $6 \cdot 7,21 \cdot 9,40 \cdot 1$ and $75 \cdot 6 \%$, respectively ( $11 \cdot 1,31 \cdot 1,55 \cdot 0$ and $84.0 \%$ in winter, respectively). Supplement users had significantly higher serum $25(\mathrm{OH}) \mathrm{D}$ concentrations compared to non-users. However, $7 \cdot 5 \%$ of users had winter serum $25(\mathrm{OH}) \mathrm{D}<30 \mathrm{nmol} / \mathrm{l}$. Only $1 \cdot 3 \% \mathrm{had}$ serum $25(\mathrm{OH}) \mathrm{D}$ concentrations $>125 \mathrm{nmol} / \mathrm{l}$. These first nationally representative serum $25(\mathrm{OH}) \mathrm{D}$ data for Irish adults show that while only $6.7 \%$ had serum $25(\mathrm{OH}) \mathrm{D}<30 \mathrm{nmol} / 1$ (vitamin D deficiency) throughout the year, $40 \cdot 1 \%$ had levels considered by the Institute of Medicine as being inadequate for bone health. These prevalence estimates were much higher during winter time. While vitamin D supplement use has benefits in terms of vitamin D status, at present rates of usage (17.5\% of Irish adults), it will have only very limited impact at a population level. Food-based strategies, including fortified foods, need to be explored.
\end{abstract}

Key words: Vitamin D: Serum 25-hydroxyvitamin D: National nutrition surveys: Supplements

Vitamin D, through its active form (1,25-dihydroxyvitamin D), is essential for intestinal Ca absorption and plays a central role in maintaining $\mathrm{Ca}$ homoeostasis and skeletal integrity ${ }^{(1)}$. There is a consensus that serum 25-hydroxyvitamin $\mathrm{D}(25(\mathrm{OH}) \mathrm{D})$ should be used to assess vitamin D status, as it reflects combined dietary supply and dermal production upon exposure to UV blue (UVB) sunlight ${ }^{(2)}$. Notwithstanding the importance of on-going discussions with respect to thresholds for serum $25(\mathrm{OH}) \mathrm{D}$ that represent adequacy/insufficiency, there is widespread acknowledgement of the presence of vitamin $\mathrm{D}$ deficiency in the community and the pressing need to address this deficiency ${ }^{(3)}$

Taking indicators of bone health, including rickets and osteomalacia, bone mineral density and $\mathrm{Ca}$ absorption, for which there was sufficient evidence to provide a reasonable and supportable basis for dietary reference intake (DRI) development, the North American Institute of Medicine (IOM)'s DRI committee for Ca and vitamin D proposed a serum 25(OH)D concentration of $40 \mathrm{nmol} / 1$ as the median value above which approximately half the population might meet its vitamin $\mathrm{D}$ requirement (and below which half might not) and $50 \mathrm{nmol} / 1$ as its estimate of the serum $25(\mathrm{OH}) \mathrm{D}$ concentration that would meet the requirement of nearly all (i.e. $97.5 \%$ ) normal healthy persons $^{(4)}$. These serum $25(\mathrm{OH}) \mathrm{D}$ concentrations were used to specify estimated average requirement (EAR) values for vitamin D intakes of $400 \mathrm{IU} / \mathrm{d}(10.0 \mu \mathrm{g} / \mathrm{d})$ in all age and sex subgroups in the population for more than 1 year, assuming minimal UVB sunlight exposure, and from which RDA values were derived for application to individuals (600 and $800 \mathrm{IU} / \mathrm{d}$ (15.0 and $20.0 \mu \mathrm{g} / \mathrm{d}$ ) of vitamin D for those aged $1-70$ and $70+$

Abbreviations: 25(OH)D, 25-hydroxyvitamin D; DEQAS, Vitamin D External Quality Assessment Scheme; DRI, dietary reference intake; EAR, estimated average requirements; IOM, Institute of Medicine; NANS, National Adult Nutrition Survey; NHANES, National Health and Nutritional Examination Survey; UVB, UV blue. 
years, respectively). Furthermore, the DRI committee suggested that persons are at risk of deficiency when serum $25(\mathrm{OH}) \mathrm{D}$ concentrations are $<30 \mathrm{nmol} / 1$ and that there may be some reason for concern at serum concentrations $>125 \mathrm{nmol} / \mathrm{l}^{(4)}$.

While the National Health and Nutritional Examination Survey (NHANES) in the USA ${ }^{(5)}$ and the Canadian Health Measures Survey ${ }^{(6)}$ have provided useful descriptions of vitamin D status in North America, equivalent data for the European Union are of variable quality, making it difficult to estimate the prevalence of vitamin D deficiency across member states. Knowledge of the distributions of serum $25(\mathrm{OH}) \mathrm{D}$ concentrations and vitamin D intakes (and their contributory food sources) in the nationally representative populations is critical for the quantification of vitamin D deficiency in the European Union population as well as for devising food-based strategies for its prevention ${ }^{(3)}$. The importance of vitamin $\mathrm{D}$ nutritional status and the need to monitor it within populations was highlighted well over a decade ago by the European Commission in its Report on Osteoporosis in the European Community: Action for Prevention ${ }^{(7)}$.

As Ireland resides at the latitude band of $51-55^{\circ} \mathrm{N}$, there are about 5 months during which UVB-induced dermal synthesis of vitamin $\mathrm{D}$ will not occur ${ }^{(8,9)}$. While there have been two previous representative surveys of food consumption at the individual level in Irish adults (in $1990^{(10)}$ and 1997-1999(11) , and thus estimates for habitual intake of vitamin D exist, only the recent National Adult Nutrition Survey (NANS) included blood samples for the analysis of nutritional status as well as collection of data on food and supplement consumption and nutrient intakes ${ }^{(12)}$. To date, data on serum $25(\mathrm{OH}) \mathrm{D}$ concentrations in healthy Irish adults have come from relatively small cross-sectional as well as intervention studies ${ }^{(13-21)}$.

Following a key recommendation in the 1998 European Commission Osteoporosis $\operatorname{Report}^{(7)}$ in relation to $\mathrm{Ca}$ and vitamin $\mathrm{D}$ education of the general public and health professionals, there has been some progress on such awareness campaigns in Ireland ${ }^{(22)}$. Whiting et al. ${ }^{(6)}$ recently showed that vitamin D supplement use in Canadians was associated with higher serum $25(\mathrm{OH}) \mathrm{D}$ concentrations as well as an attenuated effect of season on vitamin D status. Therefore, the aims of the present study were first, to characterise serum $25(\mathrm{OH}) \mathrm{D}$ concentration in the NANS participants, and second, to explore the impact of vitamin D supplement use on achieving serum $25(\mathrm{OH}) \mathrm{D}$ above cut-offs proposed by the DRI committee in these adults stratified by age, sex and season of sampling.

\section{Subjects and methods}

Subject sampling and recruitment procedures and methods of data collection

A detailed description of the methodology used in the NANS has been reported elsewhere ${ }^{(12)}$. However, a concise overview of salient aspects of subject sampling and recruitment procedures, as well as methods of data collection and laboratory analysis pertinent to the objectives of the present work, are outlined later.

\section{Ethics approval}

The study was approved by the Clinical Research Ethics Committee of the Cork Teaching Hospitals, University College Cork and the Human Ethics Research Committee of University College Dublin.

\section{Sampling procedure, inclusion/exclusion criteria and sample recruitment}

The fieldwork phase of the NANS was carried out between October 2008 and April 2010, providing a seasonal balance to the data and biological sample collection. To achieve a nationally representative sample of community-dwelling adults aged 18 years and over, a quota sampling approach was adopted using data from the most recently published census $^{(23)}$. Criteria used to achieve the quota sample were sex (50:50) within each age group (18-35 years (35\%), 36-50 years (29\%), 51-64 years (21\%) and $\geq 65$ years (15\%)). As the Republic of Ireland does not have a national identification system for adults, a database of names and addresses held by Data Ireland (National Postal Service) was used to randomly select persons in twenty geographical clusters across the country, selected to provide proportional representation across the urban-rural continuum by distinguishing cities from towns, villages and open countryside.

A sample of 1500 free-living adults to represent a population of 4.239 million people participated in the dietary survey. The sample size was chosen to deliver at least 100 individuals in the least populated age and sex sub-groups. There were few exclusion criteria, other than pregnancy/lactation and inability to complete the survey due to disability, as described previously ${ }^{(24)}$. An introductory letter plus an information leaflet were posted to each person selected from the database. Shortly after this mail contact, a researcher called to each potential respondent's home to introduce the survey and invite participation. If the person agreed to participate, a consent form was signed and the study protocol commenced. If the person was not at home, the researcher called on three more occasions on different days and at different times, before excluding them as non-contactable. If the person declined to participate in the survey, the researcher attempted to obtain information such as age, education and occupation, in order to describe non-respondents. All eligible and willing participants gave their written consent according to the Helsinki declaration.

The final response rate for the survey was 59.6\%. Analysis of the demographic features in this sample has shown it to be a representative sample of Irish adults with respect to age, sex, social class and geographical location when compared to census data ${ }^{(23)}$. Participation in the survey did not require provision of a blood sample. Of those that completed the $4 \mathrm{~d}$ food diary, $75.5 \%$ of respondents ( $n$ 1132) provided a blood sample (of which $79 \%$ were fasting). The following were the reasons why about one-quarter of the entire sample did not supply a blood sample: time constraints, lack of interest in this aspect, fear of needles, unsuccessful attempt or illness. The demographic features of the group of 
participants who provided a blood sample and those in the entire sample are shown in Table S1 (available online).

\section{Food intake data collection, food quantification and estimation of nutrient intake}

A $4 \mathrm{~d}$ food diary was used to collect food and beverage intake data, as described in detail elsewhere ${ }^{(12)}$. A quantification protocol that had been established by the Irish Universities Nutrition Alliance for the North/South Ireland Food Consumption Survey (in 1997-99 ${ }^{(11)}$ ), and described in detail elsewhere ${ }^{(25)}$, was updated for the NANS. Food intake data were analysed using WISP ${ }^{(}$(Tinuviel Software), which uses data from McCance and Widdowson's The Composition of Foods, sixth and fifth editions plus all nine supplemental volumes to generate nutrient intake data, as described elsewhere ${ }^{(12,26)}$. Modifications were made to the food composition database to include recipes of composite dishes, nutritional supplements, generic Irish foods that were commonly consumed and new-foods on the market, including vitamin D-fortified foods $^{(27)}$

\section{Participant questionnaires and anthropometry}

All participants completed questionnaires which collected information on the respondent's socio-demographics, education levels, attitudes to their own diet and weight and supplement usage, as described in detail elsewhere ${ }^{(12)}$. Information on social class and education level, smoking status, alcohol intake and medication usage (including those which contained nutrients) was also collected. Seasonality was based on the date the respondents provided the blood sample - November to March (representing the 'winter' period) or April to October (representing the 'summer' period) - consistent with studies based on NHANES ${ }^{(5)}$ and the recent analysis of Canadian Health Measures Survey for vitamin $\mathrm{D}$ status $^{(6)}$. Anthropometric measures including height, weight, waist and hip circumference and measures of body composition were taken in the respondent's homes, as described previously ${ }^{(12)}$.

\section{Assessment of vitamin D-containing supplement consumption}

Present supplement use was assessed by the respondents' answer to the question 'Do you take any vitamin, mineral or food supplements?', which was included in the self-administered health and lifestyle questionnaire. Respondents also entered each supplement, as it was consumed, into the $4 \mathrm{~d}$ food diary. Researchers checked that respondents who had reported using supplements in the questionnaire, which was administered at the start of the recording period, entered the supplements into the food diary when they were consumed. Information on product brand name, nutrient composition, as well as daily dose and frequency of consumption was obtained for each supplement taken. Researchers entered supplements into the food consumption database in the same way as they entered foods from the $4 \mathrm{~d}$ diaries. In this way, supplement consumption was measured alongside food consumption. By accounting for contribution of vitamin D from supplemental forms, the vitamin D intake data from all sources (food and supplements) as well as from food sources only were generated.

\section{Blood collection and analysis of serum 25-hydroxyvitamin D}

Blood samples were collected by venepuncture into a vacutainer tube by a qualified nurse at designated centres within the survey area or in the respondent's home if the respondent could not travel. Blood samples were transported to the laboratory for further processing and serum was stored at $-80^{\circ} \mathrm{C}$ until required for analysis. The $25(\mathrm{OH}) \mathrm{D}$ concentrations were measured at University College Cork in all serum samples using an ELISA (OCTEIA ${ }^{\circledR}$ 25-Hydroxy Vitamin D, Immuno Diagnostic Systems Limited). The intra- and inter-assay CV for the ELISA method was 5.9 and $6.6 \%$, respectively. This ELISA assay is used for the quantitative determination of serum/ plasma $25(\mathrm{OH}) \mathrm{D}$; further details have been described previously $^{(28)}$. The quality and accuracy of serum $25(\mathrm{OH}) \mathrm{D}$ analysis in our laboratory are assured on an ongoing basis by participation in the Vitamin D External Quality Assessment Scheme (DEQAS, Charing Cross Hospital, London, UK). A comparison of the performance of the present ELISA assay with that of liquid chromatography-MS in relation to DEQAS ( $n$ 20) samples for 2008 shows a high correlation (ELISA $=1.0258 \times$ liquid chromatography-MS $=3.0351 ; r 0.96)$. Measured serum $25(\mathrm{OH}) \mathrm{D}$ concentrations were compared with cut-offs for $25(\mathrm{OH}) \mathrm{D}$ as per the IOM DRI committee's recent definitions: persons are at risk of deficiency at serum 25(OH)D concentrations below $30 \mathrm{nmol} / 1$, and 40 and $50 \mathrm{nmol} / 1$ are consistent with the EAR-like and RDA-like serum values, respectively ${ }^{(4)}$. In addition, serum 25(OH)D concentrations $>125 \mathrm{nmol} / 1$ have been suggested by the IOM DRI committee as being possibly some reason for concern ${ }^{(4)}$. As the Task Force for the Clinical Guidelines Subcommittee of The Endocrine Society have recently suggested that to maximise the effect of vitamin $\mathrm{D}$ on $\mathrm{Ca}$, bone and muscle metabolism, serum $25(\mathrm{OH}) \mathrm{D}$ concentration should exceed $75 \mathrm{nmol} / \mathrm{l}^{(29)}$, we also used this cut-off for comparison purposes.

\section{Comparison of the mathematically modelled seasonal variation in serum 25-hydroxyvitamin D due to sun exposure with observed data from the National Adult Nutrition Survey}

Diffey $^{(30)}$ recently published a mathematical model which predicts the changes in serum $25(\mathrm{OH}) \mathrm{D}$ concentration arising from exposure to UVB sunlight over the course of twelve calendar months. The model uses estimates and data on response of serum $25(\mathrm{OH}) \mathrm{D}$ following a specified exposure to UVB sunshine (accounting for synthesis and decay rates for serum 25(OH)D) and incorporates UK data on daylight hours, annual standard erythema dose (standardised measure of erythemogenic UV radiation (representative of the South of England)), as well as hours spent outside per d. We used 
Diffey's model, but substituted Irish data for mean hours of sunlight in Ireland. We also made two broad assumptions in using Diffey's model and some of his estimates: as most of the Republic of Ireland (coverage area for the NANS) resides between approximately 51 and $54^{\circ} \mathrm{N}$, we used the UK standard erythema dose data which was representative for the South of England (as standard erythema dose data is not available for Ireland), and as the NANS survey did not assess the average time spent outdoors, we used the estimates from the UK adult data of Hyppönen \& Power ${ }^{(31)}$, as per Diffey ${ }^{(30)}$.

\section{Data manipulation and statistical analysis}

Data manipulation was conducted using SPSS $^{\odot}$ version 15.0 for Windows $^{\mathrm{TM}}$ (SPSS, Inc.). The $\chi^{2}$ analyses were performed to compare demographic data for the entire NANS sample ( $n$ 1500) and those NANS participants who provided a blood sample ( $n$ 1132). Descriptive statistics (frequencies, means) were used to estimate serum $25(\mathrm{OH}) \mathrm{D}$ concentrations by threshold, supplement use, age group, sex and season of blood sample collection. All estimates were based on data weighted to represent the Irish adult population aged 18-84 years $^{(23)}$. Variance estimates $(95 \% \mathrm{CI})$ were calculated, and unpaired $t$ tests were used to test differences between prevalence and mean estimates of serum 25(OH)D and mean daily vitamin D intakes. Statistical significance was defined as $P<0.05$.

\section{Results}

There was no significant difference in key demographic characteristics among the entire NANS sample ( $n$ 1500) and the subset of NANS participants who provided a blood sample ( $n$ 1132; see Table S1; available online).

Essentially all (99.5\%) the NANS adults in the present analysis ( $n$ 1132) were self-reported Caucasians, and because of the extremely small sample size of either self-reported
non-Caucasians ( $n$ 3) or those that did not specify their ethnicity ( $n$ 3), these were not treated separately in the analyses. As fasting $v$. non-fasting blood sample was not a significant determinant $(P=0.886)$ of serum $25(\mathrm{OH}) \mathrm{D}$ concentration after accounting for age, sex and month of sampling, all serum $25(\mathrm{OH}) \mathrm{D}$ data were included in the analyses.

The mean serum 25(OH)D concentration in Irish adults ( $n$ 1132) sampled throughout the year was $60 \cdot 0$ (95\% CI 58.6, $61.4) \mathrm{nmol} / \mathrm{l}$. The $2 \cdot 5 \mathrm{th}, 5 \mathrm{th}, 10 \mathrm{th}, 25 \mathrm{th}, 50 \mathrm{th}, 75 \mathrm{th}, 90 \mathrm{th}, 95 \mathrm{th}$ and $97 \cdot 5$ th percentile of year-round serum $25(\mathrm{OH}) \mathrm{D}$ were $26 \cdot 0,28 \cdot 5,32 \cdot 3,41 \cdot 5,57 \cdot 2,74 \cdot 3,92 \cdot 0,102 \cdot 0$ and $111 \cdot 8 \mathrm{nmol} / 1$, respectively. The mean serum $25(\mathrm{OH}) \mathrm{D}$ concentration in summer ( $n$ 632) and winter ( $n$ 500) was 65.5 (95\% CI 63.6, $67 \cdot 4) \mathrm{nmol} / \mathrm{l}$ and $53 \cdot 1(95 \%$ CI $51 \cdot 2,55 \cdot 1) \mathrm{nmol} / \mathrm{l}$, respectively $(P<0.0001)$. The mean daily intake of vitamin $\mathrm{D}$ from food sources only and from all sources (food and supplements) of the Irish adults ( $n$ 1132) was 160 (95\% CI 153, 166) and 219 (95\% CI 201, 237) IU/d (4.0 (95\% CI 3.8, 4.2) and $5.5(5 \cdot 0$, 5.9) $\mu \mathrm{g} / \mathrm{d})$, and did not differ by season $(P=0.518$ and $P=0.494$ for all sources and food sources only, respectively), accounting for age and sex (data not shown).

The impact of UVB sun exposure on predicted serum $25(\mathrm{OH}) \mathrm{D}$ concentrations from March to September (representing a period when vitamin D status should rise from its nadir to close to its peak $\left.{ }^{(8,9)}\right)$ is shown in Fig. 1. The observed mean monthly serum $25(\mathrm{OH}) \mathrm{D}$ concentrations for this period in those NANS participants not taking a vitamin D-containing supplement (and thus relying on dietary and dermal sources) aligned closely with predicted values arising from Diffey's mathematical model ${ }^{(30)}$, which assumes a constant input of vitamin $\mathrm{D}$ from non-dermal sources (i.e. diet and possibly stores). The difference between mean observed serum 25(OH)D concentrations in those sampled in March and September was $32 \mathrm{nmol} / 1$, and the corresponding average difference was $36 \mathrm{nmol} / 1$ using the predicted values from the model arising from increased dermal synthesis of vitamin D on exposure to UVB sunlight from March to September.

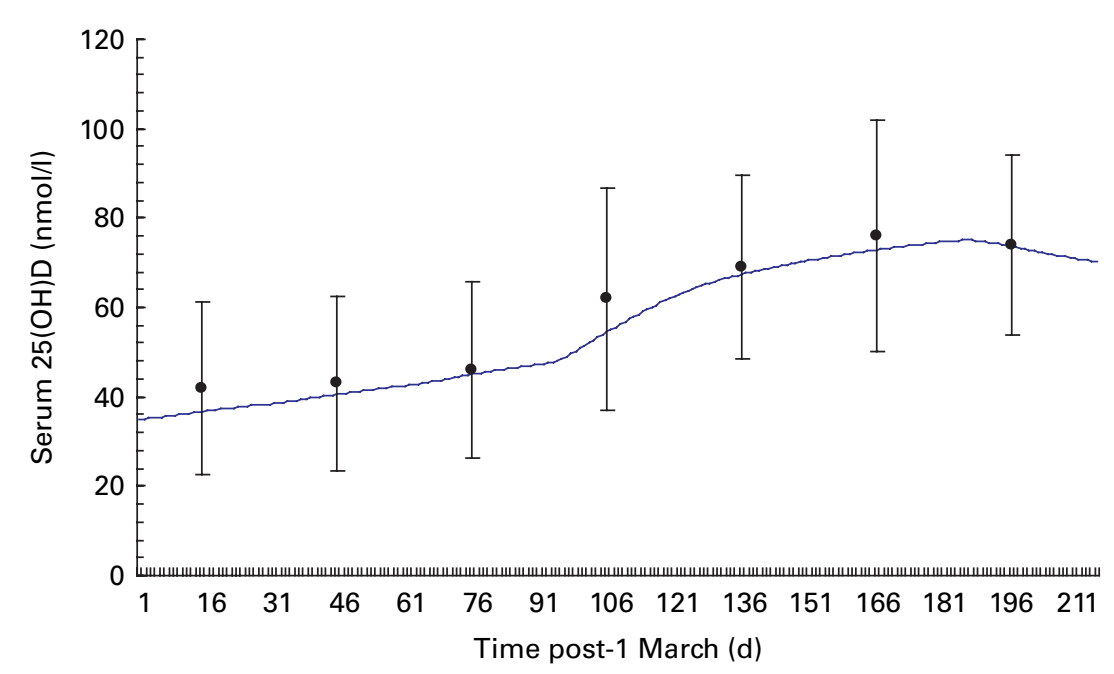

Fig. 1. Modelled variation in serum 25 -hydroxyvitamin $\mathrm{D}(25(\mathrm{OH}) \mathrm{D})$ from March to September for the Republic of Ireland (solid curve) using Diffey's model ${ }^{(30)}$ and the mean (SD) monthly measured serum 25(OH)D concentrations (data points with error bars) for adults in the National Adult Nutrition Survey. (A colour version of this figure can be found online at http://www.journals.cambridge.org/bjn) 
The prevalence rates for serum $25(\mathrm{OH}) \mathrm{D}$ concentration below the IOM DRI committee thresholds, stratified by season and sex (where sample number allowed for meaningful comparisons), are shown in Table 1. Year-round prevalence rates for serum $25(\mathrm{OH}) \mathrm{D}$ concentration $<30$, $<40$ and $<50 \mathrm{nmol} / 1$ were $6 \cdot 7,21.9$ and $40 \cdot 1 \%$, respectively (Table 1). The prevalence of vitamin D deficiency (serum $25(\mathrm{OH}) \mathrm{D}<30 \mathrm{nmol} / \mathrm{l})$ was $11 \cdot 1 \%$ in the total group of adults in winter, and with no difference between those aged 18-64 years and $>65$ years (data not shown). This dropped to $3.4 \%$ in summer. For serum $25(\mathrm{OH}) \mathrm{D}<40 \mathrm{nmol} / 1$ (the EAR-like concentration), prevalence estimates more than doubled from $15.4 \%$ in summer to $31.1 \%$ in winter. For serum $25(\mathrm{OH}) \mathrm{D}<50 \mathrm{nmol} / \mathrm{l}$ (the RDA-like concentration), estimates ranged from $21.5 \%$ (in those aged $51-64$ years old in summer) to $58.7 \%$ (in those aged $36-50$ years in winter). Even in summer, when status would be at its best for most people, between 21.5 and $35.8 \%$ had serum $25(\mathrm{OH}) \mathrm{D}$ concentrations $<50 \mathrm{nmol} / 1$ (Table 1). The prevalence of serum $25(\mathrm{OH}) \mathrm{D}<50 \mathrm{nmol} / \mathrm{l}$ in winter was lowest in the $65+$ years age category ( $48 \cdot 1 \%)$ compared to younger age categories $(54.4-58.7 \%)$, but this trend was reversed in summer with the highest prevalence in the $65+$ years olds $(35.8 \%$; Table 1). Year-round, winter and summer prevalence rates for serum 25(OH)D concentration $<75 \mathrm{nmol} / 1$ in the entire cohort of Irish adults ( $n$ 1132) were 75.6, 84.0 and 69.0\%, respectively.

For each of the IOM DRI committee serum 25(OH)D cutoffs used in the present analysis $(<30,<40$ and $<50 \mathrm{nmol} / \mathrm{l})$, the differences in prevalence estimates between winter and summer (significant in all cases) were of a much greater magnitude (1.9-3.2 times higher in winter, for all adults) compared to differences in prevalence estimates between sexes within a season (typically less than 20\%, and nonsignificant differences in all cases; Table 1).

A total of fifteen persons (eight men and seven women; $1.3 \%)$ had serum $25(\mathrm{OH}) \mathrm{D}$ concentrations $>125 \mathrm{nmol} / \mathrm{l}$, a serum threshold which according to the DRI committee may be some reason for concern ${ }^{(4)}$. Of these, eleven were sampled in summer and of the four that were sampled in winter, two were supplement users (667 and $2000 \mathrm{IU} / \mathrm{d}$ (16.7 and $50.0 \mu \mathrm{g} / \mathrm{d}$ ), respectively) and one of the two nonusers had been on a sun vacation before sampling.

Of the entire cohort of Irish adults aged 18-84 years, 17.5\% were taking a vitamin D-containing supplement. Vitamin D-containing supplement use was higher in women $(55.6 \%)$ than men $(44.4 \%)$, and in older ( $>65$ years; $27.6 \%)$ than younger adults (18-65 years; 16.0\%). The median (min, max) content of the vitamin D-containing supplements was $200(10,2412)$ IU $(5 \cdot 0(0 \cdot 25,60 \cdot 3) \mu \mathrm{g})$ vitamin D. Among the supplement users, $67 \cdot 2$ and $15 \cdot 1 \%$ took $\leq 200 \mathrm{IU} / \mathrm{d}(5 \cdot 0 \mu \mathrm{g} / \mathrm{d})$ and between 200 and $\leq 400 \mathrm{IU} / \mathrm{d}(5.0$ and $\leq 10.0 \mu \mathrm{g} / \mathrm{d})$ as supplemental vitamin $\mathrm{D}$, respectively. Only a small percentage (3.5\%) of the total population had supplemental intakes of vitamin $\mathrm{D} \geq 1000 \mathrm{IU} / \mathrm{d}(25 \cdot 0 \mu \mathrm{g} / \mathrm{d})$ and these were mostly aged $>50$ years, and mostly female (data not shown).

The association between vitamin D-containing supplement use and serum $25(\mathrm{OH}) \mathrm{D}$ concentration by season was also examined (Table 2). Seasonal differences in mean serum $25(\mathrm{OH}) \mathrm{D}$ concentration were evident in supplement nonusers but not in supplement users. For example, the change in mean serum $25(\mathrm{OH}) \mathrm{D}$ with seasonality (summer less winter) was $13.9 \mathrm{nmol} / 1$ in supplement non-users and $5 \cdot 1 \mathrm{nmol} / 1$ in users. Overall, in both winter and summer, supplement users had higher serum 25(OH)D concentrations than did non-users. Interestingly, the mean winter serum $25(\mathrm{OH}) \mathrm{D}$ concentration in vitamin D-containing supplement

Table 1. Distribution of subjects by serum 25 -hydroxyvitamin $\mathrm{D}(25(\mathrm{OH}) \mathrm{D})$ concentration, season and sex in the National Adult Nutrition Survey of adults aged 18-84 years in Ireland, 2008-10* $† \ddagger$

(Number of subjects, percentages and $95 \%$ confidence intervals)

\begin{tabular}{|c|c|c|c|c|c|c|c|c|c|}
\hline \multirow[b]{2}{*}{ Serum $25(\mathrm{OH}) \mathrm{D}$ concentration } & \multicolumn{3}{|c|}{ Year round } & \multicolumn{3}{|c|}{ Winter } & \multicolumn{3}{|c|}{ Summer } \\
\hline & $n$ & $\%$ & $95 \% \mathrm{Cl}$ & $n$ & $\%$ & $95 \% \mathrm{Cl}$ & $n$ & $\%$ & $95 \% \mathrm{Cl}$ \\
\hline \multicolumn{10}{|l|}{$<30 \mathrm{nmol} / \mathrm{l}$} \\
\hline Age $18-84$ years & 77 & $6 \cdot 7$ & $5 \cdot 2,8 \cdot 3$ & 57 & $11 \cdot 1$ & $8.6,13.5$ & 20 & 3.4 & $2 \cdot 1,4 \cdot 7$ \\
\hline Female & 34 & $6 \cdot 0$ & $4.5,7.5$ & 23 & $10 \cdot 3$ & $7 \cdot 8,12 \cdot 8$ & 11 & 3.4 & $2 \cdot 1,4 \cdot 7$ \\
\hline Male & 43 & 7.4 & $5 \cdot 8,9 \cdot 0$ & 34 & $11 \cdot 8$ & $9 \cdot 3,14 \cdot 2$ & 9 & 3.4 & $2 \cdot 0,4 \cdot 7$ \\
\hline \multicolumn{10}{|l|}{$<40 \mathrm{nmol} / \mathrm{l}$} \\
\hline Age $18-84$ years & 250 & 21.9 & $18 \cdot 2,25 \cdot 5$ & 156 & 31.1 & $26 \cdot 7,35 \cdot 5$ & 94 & $15 \cdot 4$ & $12 \cdot 3,18 \cdot 5$ \\
\hline Female & 127 & $22 \cdot 3$ & $18 \cdot 3,26 \cdot 3$ & 71 & 32.6 & $26 \cdot 6,37.5$ & 56 & $16 \cdot 0$ & $12 \cdot 6,19 \cdot 4$ \\
\hline Male & 123 & $21 \cdot 4$ & $18 \cdot 1,24 \cdot 7$ & 85 & $29 \cdot 6$ & $25 \cdot 7,33 \cdot 6$ & 38 & $14 \cdot 8$ & $12 \cdot 1,17 \cdot 4$ \\
\hline \multicolumn{10}{|l|}{$<50 \mathrm{nmol} / \mathrm{l}$} \\
\hline Age $18-84$ years & 453 & $40 \cdot 1$ & $35 \cdot 3,44.9$ & 273 & 55.0 & $49 \cdot 2,60 \cdot 8$ & 180 & 28.9 & $24 \cdot 7,33 \cdot 1$ \\
\hline Female & 222 & 39.4 & $34.2,44.5$ & 121 & 55.5 & $50 \cdot 2,60 \cdot 7$ & 101 & 29.9 & $25 \cdot 3,34 \cdot 4$ \\
\hline Male & 231 & $40 \cdot 8$ & $36 \cdot 4,45 \cdot 2$ & 152 & 54.5 & $48 \cdot 1,61 \cdot 0$ & 79 & 28.0 & $24 \cdot 2,31 \cdot 8$ \\
\hline Age $18-35$ years & 181 & $42 \cdot 2$ & $37 \cdot 7,46 \cdot 7$ & 110 & 54.4 & $49 \cdot 1,59 \cdot 6$ & 71 & $31 \cdot 3$ & $27 \cdot 1,35 \cdot 4$ \\
\hline Age $36-50$ years & 129 & $38 \cdot 3$ & $33 \cdot 1,43.6$ & 68 & $58 \cdot 7$ & $51 \cdot 3,66 \cdot 0$ & 61 & $27 \cdot 6$ & $23 \cdot 4,31 \cdot 8$ \\
\hline Age $51-64$ years & 80 & $35 \cdot 7$ & $32 \cdot 4,39 \cdot 0$ & 52 & 55.4 & $51 \cdot 4,59 \cdot 4$ & 28 & 21.5 & $18 \cdot 8,24 \cdot 2$ \\
\hline Age $65-84$ years & 63 & 44.0 & $41 \cdot 5,46.5$ & 43 & 48.1 & $45 \cdot 1,51 \cdot 0$ & 20 & $35 \cdot 8$ & $34 \cdot 1,37 \cdot 6$ \\
\hline
\end{tabular}

* There was a significant difference between winter and summer for all age and sex categories $(P<0.01)$.

† There were no significant differences between males and females ( $P>0.1$ in all cases; unpaired $t$ test).

$\ddagger$ Division into age groupings only possible for serum $25(\mathrm{OH}) \mathrm{D}<50 \mathrm{nmol} / \mathrm{l}$, as base numbers too low for other two serum $25(\mathrm{OH}) \mathrm{D}$ categories. 
Table 2. Serum 25-hydroxyvitamin D $(25(\mathrm{OH}) \mathrm{D})$ concentration by vitamin D-containing supplement use, season, sex and age group in subjects in the National Adult Nutrition Survey of adults aged 18-84 years in Ireland, 2008-2010

(Mean values, number of subjects and $95 \%$ confidence intervals)

\begin{tabular}{|c|c|c|c|c|c|c|c|c|c|c|c|c|}
\hline & \multicolumn{6}{|c|}{ Winter } & \multicolumn{6}{|c|}{ Summer } \\
\hline & \multicolumn{3}{|c|}{ Supplement use } & \multicolumn{3}{|c|}{ No supplement use } & \multicolumn{3}{|c|}{ Supplement use } & \multicolumn{3}{|c|}{ No supplement use } \\
\hline & $n$ & Mean & $95 \% \mathrm{Cl}$ & $n$ & Mean & $95 \% \mathrm{Cl}$ & $n$ & Mean & $95 \% \mathrm{Cl}$ & $n$ & Mean & $95 \% \mathrm{Cl}$ \\
\hline \multicolumn{13}{|c|}{ Age (years) } \\
\hline $18-84$ & 88 & $66 \cdot 1^{*}$ & $60 \cdot 7,71 \cdot 4$ & 412 & $50 \cdot 4$ & $48 \cdot 4,52 \cdot 4$ & 110 & $71 \cdot 2^{\star}$ & $66 \cdot 7,75 \cdot 7$ & 522 & $64.3 \dagger$ & $62 \cdot 2,66 \cdot 4$ \\
\hline $18-35$ & 31 & $65 \cdot 6^{\star}$ & $55 \cdot 9,75 \cdot 3$ & 172 & 50.8 & $47 \cdot 8,53 \cdot 8$ & 24 & $64 \cdot 0$ & $54 \cdot 7,73 \cdot 3$ & 203 & 64.3† & $61 \cdot 0,67 \cdot 6$ \\
\hline $36-50$ & 16 & $62 \cdot 3^{\star}$ & $50 \cdot 3,74.3$ & 99 & $49 \cdot 7$ & $45 \cdot 7,53 \cdot 7$ & 30 & 69.7 & $62 \cdot 9,76.5$ & 188 & $66.8 \dagger$ & $63.1,70.5$ \\
\hline $51-64$ & 19 & $66 \cdot 2^{\star}$ & $54 \cdot 6,77 \cdot 8$ & 75 & $50 \cdot 7$ & $45 \cdot 7,55 \cdot 6$ & 38 & $74 \cdot 1^{*}$ & $68 \cdot 2,80 \cdot 0$ & 92 & $63.3 \dagger$ & $59 \cdot 0,67.5$ \\
\hline $65-84$ & 22 & $69 \cdot 2^{*}$ & $57.5,80.9$ & 66 & $49 \cdot 6$ & $44 \cdot 3,54 \cdot 8$ & 18 & $77 \cdot 4^{*}$ & $57 \cdot 9,96 \cdot 8$ & 39 & $54 \cdot 7 \ddagger$ & $48 \cdot 3,61 \cdot 1$ \\
\hline
\end{tabular}

* Mean values were significantly different from no supplement use within same season $(P<0.05$; unpaired $t$ test).

$\dagger$ Mean values were significantly different from no supplement use in winter $(P<0.001$; unpaired $t$ test).

$\ddagger$ Mean values were significantly different from supplement use in winter $(P<0.05$; unpaired $t$ test); there was no significant difference between summer and winter for supplement users $(P>0.1$ in all cases).

users $(66 \cdot 1 \mathrm{nmol} / \mathrm{l})$ was similar to that achieved by non-users in summer $(64.3 \mathrm{nmol} / 1, P>0 \cdot 1$; Table 2$)$. The mean daily intake of vitamin $\mathrm{D}$ from food sources only did not differ between supplement users and non-users in either season after accounting for age and sex $(P>0 \cdot 2$; data not shown).

Prevalence of serum 25(OH)D concentration below 30, 40 and $50 \mathrm{nmol} / 1$ for year-round and winter only, and stratified by supplement use, are shown in Table 3 . In general, the highest prevalence of low status (less than 30, 40 and $50 \mathrm{nmol} / \mathrm{l}$ ) was in non-users in winter, and supplement use was associated with lower prevalence estimates during winter, irrespective of which threshold of serum $25(\mathrm{OH}) \mathrm{D}$ was used. However, caution is warranted as the numbers in some of the sub-groups are quite low.

When the total group of adults was stratified into those with habitual vitamin D intakes (irrespective of whether from food alone or food plus supplements) above and below the IOM dietary EAR for vitamin D $\left(400 \mathrm{IU} / \mathrm{d}(10.0 \mu \mathrm{g} / \mathrm{d})^{(4)}\right)$, the preva-

Table 3. Distribution of subjects taking a vitamin D-containing supplement, by serum 25-hydroxyvitamin $\mathrm{D}(25(\mathrm{OH}) \mathrm{D})$ concentrations and sex in subjects in the National Adult Nutrition Survey of adults aged 18-84 years in Ireland, 2008-10*

(Number of subjects, percentages and $95 \%$ confidence intervals)

\begin{tabular}{|c|c|c|c|c|c|c|}
\hline \multirow[b]{2}{*}{ Serum $25(\mathrm{OH}) \mathrm{D}$ concentration } & \multicolumn{3}{|c|}{ Supplement use } & \multicolumn{3}{|c|}{ No supplement use } \\
\hline & $n$ & $\%$ & $95 \% \mathrm{Cl}$ & $n$ & $\%$ & $95 \% \mathrm{Cl}$ \\
\hline \multicolumn{7}{|l|}{ Year round } \\
\hline \multicolumn{7}{|l|}{$<30 \mathrm{nmol} / \mathrm{l}$} \\
\hline Age $18-84$ years & 6 & $3.7 \dagger$ & $1 \cdot 0,6 \cdot 3$ & 70 & $7 \cdot 6$ & $5 \cdot 8,9 \cdot 4$ \\
\hline Female & 3 & $3 \cdot 8 \mp \S$ & $1 \cdot 3,6 \cdot 4$ & 30 & $6 \cdot 8$ & $5 \cdot 0,8 \cdot 6$ \\
\hline Male & 3 & $3.5 \pm \S$ & $0 \cdot 7,6 \cdot 3$ & 40 & 8.3 & $6 \cdot 5,10 \cdot 1$ \\
\hline \multicolumn{7}{|l|}{$<40 \mathrm{nmol} / \mathrm{l}$} \\
\hline Age $18-84$ years & 19 & $10 \cdot 1 \dagger$ & $5 \cdot 3,15 \cdot 0$ & 229 & 24.5 & $21 \cdot 1,28 \cdot 4$ \\
\hline Female & 11 & $11.3 \dagger$ & $6 \cdot 1,16 \cdot 5$ & 115 & $25 \cdot 4$ & $21 \cdot 3,29 \cdot 7$ \\
\hline Male & 8 & $8.9 \dagger$ & $4 \cdot 5,13 \cdot 4$ & 114 & 24.0 & $21 \cdot 0,27 \cdot 1$ \\
\hline \multicolumn{7}{|l|}{$<50 \mathrm{nmol} / \mathrm{l}$} \\
\hline Age $18-84$ years & 46 & $24 \cdot 2 \dagger$ & $16 \cdot 6,32 \cdot 1$ & 405 & 43.8 & $39 \cdot 1,48.5$ \\
\hline Female & 24 & $23 \cdot 2 \dagger$ & $15 \cdot 2,31 \cdot 2$ & 197 & 43.9 & $38 \cdot 6,49 \cdot 2$ \\
\hline Male & 22 & $25.4 \dagger$ & $18 \cdot 1,32 \cdot 8$ & 208 & 43.6 & $39 \cdot 5,47 \cdot 7$ \\
\hline \multicolumn{7}{|l|}{ Winter only } \\
\hline \multicolumn{7}{|l|}{$<30 \mathrm{nmol} / \mathrm{l}$} \\
\hline Age $18-84$ years & 5 & $7.5 \pm \S$ & $1 \cdot 8,13 \cdot 1$ & 51 & $12 \cdot 1$ & $8 \cdot 6,15 \cdot 6$ \\
\hline Female & 3 & $11 \cdot 1 \ddagger \S$ & $4 \cdot 4,17 \cdot 8$ & 20 & $11 \cdot 0$ & $7 \cdot 2,14 \cdot 7$ \\
\hline Male & 2 & $3.9 \pm \S$ & $0.3,8 \cdot 1$ & 31 & $13 \cdot 1$ & $9 \cdot 8,16 \cdot 4$ \\
\hline \multicolumn{7}{|l|}{$<40 \mathrm{nmol} / \mathrm{l}$} \\
\hline Age $18-84$ years & 13 & $15 \cdot 8 \dagger$ & $6 \cdot 4,25 \cdot 3$ & 142 & 34.2 & $27 \cdot 8,40 \cdot 6$ \\
\hline Female & 7 & $16 \cdot 3 \dagger$ & $5 \cdot 9,26 \cdot 7$ & 65 & 36.0 & $28 \cdot 2,43 \cdot 7$ \\
\hline Male & 6 & $15 \cdot 3 \dagger$ & $7 \cdot 0,23 \cdot 7$ & 77 & 32.4 & $27 \cdot 3,37 \cdot 5$ \\
\hline \multicolumn{7}{|l|}{$<50 \mathrm{nmol} / \mathrm{l}$} \\
\hline Age $18-84$ years & 24 & $26 \cdot 8+$ & $14 \cdot 4,39 \cdot 2$ & 248 & $59 \cdot 8$ & $51 \cdot 9,67 \cdot 8$ \\
\hline Female & 11 & $23.0 \dagger$ & $10 \cdot 0,35.9$ & 112 & $61 \cdot 2$ & $51 \cdot 9,70.5$ \\
\hline Male & 13 & $30.5 \dagger$ & $18 \cdot 9,42 \cdot 1$ & 136 & 58.4 & $51 \cdot 8,65 \cdot 8$ \\
\hline
\end{tabular}

* There were no significant differences between males and females ( $P>0.1$ in all cases; unpaired $t$ test).

$\dagger$ Significantly different from no supplement use $(P<0.05$; unpaired $t$ test).

$\ddagger$ Interpret with caution due to the base number $\leq 5$.

$\S$ Statistical analysis not performed due to the small sample size. 
lence of serum $25(\mathrm{OH}) \geq 40 \mathrm{nmol} / 1$ was much higher $(81 \%)$ in those reaching the EAR than in those failing to meet this target $(67 \%)$ in winter.

\section{Discussion}

Vitamin D status in populations living at latitudes above $40^{\circ} \mathrm{N}$ is at its lowest in the winter period, during which the capacity for UVB sunlight-induced dermal synthesis of vitamin D is much reduced and even absent ${ }^{(8,9)}$. In the present study, the prevalence of serum 25(OH)D concentration $<30 \mathrm{nmol} / 1$ (the IOM threshold for vitamin D deficiency ${ }^{(4)}$ ) during winter was $11 \cdot 1 \%$ compared to $3.4 \%$ during summer. This seasonal difference was also evident in prevalence estimates of serum 25(OH)D below the IOM DRI committee's thresholds of 40 and $50 \mathrm{nmol} / 1$, which relate to covering needs of vitamin D in half and nearly all (97.5\%) of the general healthy population, respectively ${ }^{(4)}$. Overall, the year-round prevalence estimates of serum $25(\mathrm{OH}) \mathrm{D}<30$ and $<50 \mathrm{nmol} / 1$ in Irish adults ( 6.7 and $40.1 \%$, respectively) agree well with those of the US adults aged $>19$ years in NHANES 2001-2006 $(9.1 \text { and } 34.9 \% \text {, respectively })^{(5)}$, but while the later survey included a multi-ethnic population sample, the NANS was overwhelmingly Caucasian. Non-whites in NHANES had three to approximately ten times higher year-round prevalence of serum $25(\mathrm{OH}) \mathrm{D}<30 \mathrm{nmol} / 1$ compared to whites (at 3\%) ${ }^{(5)}$. Whiting et al. ${ }^{(6)}$ recently showed in the Canadian Health Measures Survey that the year-round prevalence estimates for serum $25(\mathrm{OH}) \mathrm{D}$ concentrations $<30,<40$ and $<50 \mathrm{nmol} / 1$ were $3.0,8.7$ and $19.9 \%$, respectively, in whites and $16 \cdot 3,30.5$ and $51.4 \%$, respectively, in non-whites. Thus, prevalence estimates for these different degrees of low vitamin D status in Irish adults were much higher (about double) than that of North American Caucasians ${ }^{(5,6)}$. Data from the UK-based National Diet and Nutrition Survey of adults (18-64 years) $)^{(32)}$ show that year-round prevalence estimates of serum $25(\mathrm{OH}) \mathrm{D}<30,<40$ and $<50 \mathrm{nmol} / 1$ were $23.5,41.0$ and $55.5 \%$, respectively, while in older adults (65-84 years $)^{(33)}$, year-round prevalence estimates of serum $25(\mathrm{OH}) \mathrm{D}<30$ and $<40(<50$ not reported $)$ nmol/1 were 15.3 and $31.5 \%$, respectively. These UK surveys included a multi-ethnic population sample, but did not report serum $25(\mathrm{OH}) \mathrm{D}$ concentrations by ethnicity.

The mean serum $25(\mathrm{OH}) \mathrm{D}$ concentrations during winter in vitamin D-containing supplement users in the present study were as high as mean concentrations in non-users during summer, suggesting an ability of vitamin D supplement use to modulate an average seasonal decline of approximately $12 \mathrm{nmol} / 1$ in non-users. However, vitamin $\mathrm{D}$ deficiency (serum 25(OH)D concentrations $<30 \mathrm{nmol} / \mathrm{l}$ ) still occurred in $7.5 \%$ of vitamin D-containing supplement users in winter, and in $12.1 \%$ non-users. While these 6-month extended winter and summer periods have been used in NHANES ${ }^{(5)}$ and the Canadian Health Measures Survey ${ }^{(6)}$, and we have used for comparison purposes, this approach does not reflect true seasons as defined by the movement of the sun. In Ireland, winter would finish and spring begin by about March/April, and consequently, the nadir in serum 25(OH)D concentration would be at about March and a peak at about September/October ${ }^{(8,9)}$. This was illustrated in the present study by an average difference in mean serum $25(\mathrm{OH}) \mathrm{D}$ concentration of about $32 \mathrm{nmol} / \mathrm{l}$ between those sampled in March and September. Diffey's mathematical model of seasonal change in serum $25(\mathrm{OH}) \mathrm{D}^{(30)}$ showed a steady daily increase in serum 25(OH)D from March to the end of May, even greater daily increments during June, July and August and a possible peak by early September. Sun exposure was not assessed as part of NANS, but the observed mean monthly serum 25(OH)D concentrations were in close agreement with predicted serum $25(\mathrm{OH}) \mathrm{D}$ concentrations from the model. It is assumed within the model that dietary vitamin D intake does not change by season (an assumption strengthened by the present vitamin D intake findings), and thus the improvement in status during the extended summer period arises from increased dermal synthesis of vitamin D upon exposure to UVB sunshine. However, the risk of skin damage and cancer prohibits use of sunshine exposure as a public health measure to correct endemic low-vitamin D status. In addition, even in summer time, when status should be its highest, 3.4\% of NANS participants still had serum $25(\mathrm{OH}) \mathrm{D}$ concentrations $<30 \mathrm{nmol} / 1$ (and $28.9 \%,<50 \mathrm{nmol} / \mathrm{l}$ ). While dietary supply of vitamin D takes on increasing importance, it is low for most European populations ${ }^{(34)}$. The mean daily intake of vitamin D for the present group of Irish adults was $209 \mathrm{IU} / \mathrm{d}(5 \cdot 2 \mu \mathrm{g} / \mathrm{d})$.

The present study showed that compared to non-users, vitamin D-containing supplement use was important in achieving a higher mean serum $25(\mathrm{OH}) \mathrm{D}$ in winter $(15.7 \mathrm{nmol} / \mathrm{l}$, on average), and, albeit to a lesser degree, also in summer $(6.8 \mathrm{nmol} / 1$, on average). We have previously shown that vitamin D-containing supplement use by Irish post-menopausal women was associated with a higher serum 25(OH)D concentration in summer (as well as winter) compared to nonusers $^{(19)}$. Whiting et $a l .{ }^{(6)}$ also recently reported higher mean serum $25(\mathrm{OH}) \mathrm{D}$ concentrations among supplement users in both winter and summer.

Of note, while vitamin D-containing supplement use appeared to dramatically reduce the prevalence of serum $25(\mathrm{OH}) \mathrm{D}$ concentrations $<30,<40$ and $<50 \mathrm{nmol} / \mathrm{l} \mathrm{com}-$ pared to that in non-users in both the Canadian ${ }^{(6)}$ and Irish surveys, it did not prevent their occurrence in winter or even totally in summer. For example, even though taking a vitamin D-containing supplement, one individual (0.9\%) in the present survey and seventeen individuals (1.9\%) in the Canadian survey ${ }^{(6)}$ had serum $25(\mathrm{OH}) \mathrm{D}$ concentrations $<30 \mathrm{nmol} / 1$ in summer, as compared to a prevalence of 3.6 and $4.7 \%$ in Irish and Canadian non-users, respectively. Furthermore, despite conferring a benefit in terms of higher mean serum $25(\mathrm{OH}) \mathrm{D}$ concentrations in those adults who used vitamin D-containing supplements, it is worth re-emphasising that only $17 \cdot 5 \%$ of the Irish adults aged $18-84$ years (16\% of those aged 18-64 years) consumed them. The previous national Irish nutrition survey in 1997-1999 showed that $15 \%$ of adults aged 18-64 years consumed a vitamin D-containing supplement ${ }^{(23)}$. Such data might suggest that the efforts at increasing public and health professional awareness of vitamin D nutritional status ${ }^{(22)}$ have not translated into 
increased uptake of supplement use. Gahche et al. ${ }^{(35)}$ recently showed that rates of vitamin D-containing supplement use in the US adults aged $20-59$ years participating in various cycles of NHANES remained stable from the period 1999-2002 to 2003-2006 (average 35\%), but increased significantly in women aged $60+$ years (49.7-56.3\%, respectively), but not men. While previous data is not available to compare against, the rate of vitamin D supplement use (27.6\%) in older Irish adults ( $>65$ years) in the present survey was much higher than in younger adults. The higher use of vitamin D-containing supplements in the $65+$ age group compared to younger age groups may underpin the lower percentage of subjects with winter serum 25(OH)D less than $50 \mathrm{nmol} / \mathrm{l}$ in the former compared to later groups. However, despite the higher use of vitamin D-containing supplements in these older subjects, they had the highest prevalence of serum $25(\mathrm{OH}) \mathrm{D}$ less than $50 \mathrm{nmol} / \mathrm{l}$ during summer, likely due to a lower efficiency of dermal production of vitamin $\mathrm{D}$ upon exposure to UVB sunlight compared to younger adults ${ }^{(36,37)}$. Within the $65+$ age group, a high proportion (70\%) of the vitamin D-containing supplement users also consumed supplemental $\mathrm{Ca}$, which may reflect self- or medically prescribed supplement use for osteoporosis prevention. Also of note, and possibly a contributory factor in the better vitamin D status in North American whites, is the much higher uptake of vitamin D supplement use (between 32 and 56.3\% depending on age, sex and country) by individuals in the USA and Canada $^{(5,6)}$ compared to Ireland.

Although supplements contribute 9 and $17 \%$ to vitamin D intakes in Irish adults aged 18-64 years and $\geq 65$ years, respectively, and almost a quarter of vitamin $\mathrm{D}$ intakes in women and $12 \%$ in men in the UK adult population ${ }^{(38)}$, overall mean daily intakes of vitamin D are low, so these contributions, while proportionally high, are quantitatively low. Furthermore, evidence seems to suggest that the population intake of vitamin D from supplements in other European countries is also quite low ${ }^{(34)}$. This is a function mainly of the relatively low vitamin D content of most supplements in some countries relative to DRI, particularly the new North American values $^{(4)}$. For example, the median concentration of vitamin $\mathrm{D}$ in the supplements consumed by participants in the present survey was only $200 \mathrm{IU} / \mathrm{d}(5.0 \mu \mathrm{g} / \mathrm{d})$. Even within vitamin D-containing supplement users, 53\% failed to reach the EAR intake target for vitamin D $(400 \mathrm{IU} / \mathrm{d}$; $10.0 \mu \mathrm{g} / \mathrm{d}$ ). On the other hand, the low content possibly helped protect against serum 25(OH)D concentration $>125 \mathrm{nmol} / \mathrm{l}$, with only $1.5 \%$ of supplement users exceeding this threshold in the present survey.

With the exception of specific patient groups, supplementation as a preventive strategy is likely to have limited effectiveness in population health promotion in Europe due to relatively low compliance in some populations. It is clear that sustainable solutions to counteract the prevailing high prevalence of low vitamin D status will require appropriate food-based strategies that will prevent vitamin D inadequacy across all sectors of the population. The present findings showed how achieving the EAR of $400 \mathrm{IU}(10 \cdot 0 \mu \mathrm{g})$ vitamin D/d protected all but $19 \%$ of adults in maintaining winter-time serum $25(\mathrm{OH}) \geq 40 \mathrm{nmol} / 1$ (the average requirement for vitamin $\mathrm{D}$ in terms of bone health); however, over $85-97 \%$ of Irish adults have intakes $\leq 400 \mathrm{IU}(10 \cdot 0 \mu \mathrm{g})$, depending on age and sex group. Vitamin D fortification (mandatory or voluntarily) of food has been viewed by some as an alternative, feasible and effective measure once applied in an evidence-based approach. At present, vitamin D intake from voluntary fortified foods in Europe is low ${ }^{(34)}$, highlighting the need to explore strategies for fortification of select foods with a content of vitamin D, which will allow individuals to attain dietary targets.

In conclusion, this is the first nationally representative data on vitamin D status for Irish adults and it shows that while serum $25(\mathrm{OH}) \mathrm{D}$ concentrations reflective of vitamin $\mathrm{D}$ deficiency only occur in $6.7 \%$ of the population throughout the year, $40 \cdot 1 \%$ have levels considered by the IOM as being inadequate for bone health. These prevalence estimates are much higher during winter time. While vitamin D supplement use has benefits in terms of higher mean serum 25(OH)D concentrations and lower prevalence rates of low status, at present rates of usage (17.5\% of Irish adults), supplement use will have only very limited impact at a population level. Thus, there is a need to explore food-based strategies for improving vitamin D status, including fortified foods.

\section{Supplementary material}

To view supplementary material for this article, please visit http://dx.doi.org/10.1017/S0007114512003212

\section{Acknowledgements}

The present research was funded by the Irish Department of Agriculture, Food and the Marine and The Health Research Board under their joint Food for Health Research Initiative (2007-2). The authors' contributions were as follows: M. J. G., K. D. C. and A. F. were involved in conception of work and are grant holders; A. F., J. W., B. M., A. N. and M. J. G. contributed to study design and execution of study; S. M. and K. D. C. contributed to sample analysis; all authors contributed to data analysis and writing of manuscript. None of the authors has a conflict of interest.

\section{References}

1. UK Department of Health (1988) Nutrition and Bone Health: With Particular Reference to Calcium and Vitamin D. Report on Health and Social Subjects (49). London: The Stationery Office.

2. Cashman KD (2007) Calcium and vitamin D. Novartis Found Symp 282, 123-138.

3. Cashman KD \& Kiely M (2011) Towards prevention of vitamin D deficiency and beyond - knowledge gaps and research needs in vitamin $\mathrm{D}$ nutrition and public health. Br J Nutr 106, 1617-1627.

4. Institute of Medicine Food and Nutrition Board (2011) Dietary Reference Intakes for Calcium and Vitamin D. Washington, DC: National Academy Press. 
5. Looker AC, Johnson CL, Lacher DA, et al. (2011) Vitamin D status: United States, 2001-2006. NCHS Data Brief 59, 1-8.

6. Whiting SJ, Langlois KA, Vatanparast H, et al. (2011) The vitamin D status of Canadians relative to the 2011 Dietary Reference Intakes: an examination in children and adults with and without supplement use. Am J Clin Nutr 94, 128-135.

7. European Commission (1998) Report on Osteoporosis in the European Community: Action for Prevention. Luxembourg: Office for Official Publications for the European Commission.

8. Webb AR, Kline L \& Holick MF (1988) Influence of season and latitude on the cutaneous synthesis of vitamin $\mathrm{D}_{3}$ : exposure to winter sunlight in Boston and Edmonton will not promote vitamin $\mathrm{D}_{3}$ synthesis in human skin. $J$ Clin Endocrinol Metab 67, 373-378.

9. Webb AR \& Engelsen O (2006) Calculated ultraviolet exposure levels for a healthy vitamin D status. Photochem Photobiol 82, 1697-1703.

10. Irish Nutrition and Dietetic Institute (1990) Irish National Nutrition Survey. Dublin: Irish Nutrition and Dietetic Institute.

11. Irish Universities Nutrition Alliance (2001) North/South Ireland Food Consumption Survey. Cork: Irish Universities Nutrition Alliance. http://www.iuna.net/?P=25 (accessed 1 June 2011).

12. Irish Universities Nutrition Alliance (2011) National Adult Nutrition Survey: Summary Report. March 2011. Cork: Irish Universities Nutrition Alliance. http://www.iuna.net/wpcontent/uploads/2010/12/National-Adult-Nutrition-SurveySummary-Report-March-2011.pdf (accessed 1 June 2011).

13. Lardner E, Fitzgibbon M, Wilson S, et al. (2011) Hypovitaminosis D in a healthy female population, aged from 40 to 85 years, in the west of Ireland. Ir J Med 180, 115-119.

14. Cashman KD, Hill TR, Lucey AJ, et al. (2008) Estimation of the dietary requirement for vitamin $\mathrm{D}$ in healthy adults. Am J Clin Nutr 88, 1535-1542.

15. Cashman KD, Wallace JM, Horigan G, et al. (2009) Estimation of the dietary requirement for vitamin $\mathrm{D}$ in freeliving adults $\geq 64$ y of age. Am J Clin Nutr 89, 1366-1374.

16. O'Riordan MN, Kiely M, Higgins JR, et al. (2008) Prevalence of suboptimal vitamin D status during pregnancy. Ir Med J 10, 242-243.

17. O'Sullivan M, Nic Suibhne T, Cox G, et al. (2008) High prevalence of vitamin $\mathrm{D}$ insufficiency in healthy Irish adults. Ir J Med Sci 177, 131-134

18. Hill TR, Flynn A, Kiely M, et al. (2006) Prevalence of suboptimal vitamin D status in young, adult and elderly Irish subjects. Ir Med J 99, 48-49.

19. Hill T, Collins A, O'Brien M, et al. (2005) Vitamin D intake and status in Irish postmenopausal women. Eur J Clin Nutr 59, 404-410.

20. McKenna MJ (1992) Differences in vitamin D status between countries in young adults and the elderly. Am J Med $\mathbf{9 3}$, 69-77.

21. McKenna MJ, Freaney R, Meade A, et al. (1985) Hypovitaminosis D and elevated serum alkaline phosphatase in elderly Irish people. Am J Clin Nutr 41, 101-109.
22. International Osteoporosis Society (2008) Osteoporosis in the European Union in 2008: Ten Years of Progress and Ongoing Challenges. Nyon, Switzerland: International Osteoporosis Foundation. http://www.iofbonehealth.org/ publications/eu-policy-report-of-2008.html (accessed 1 June 2011).

23. Kiely M, Flynn A, Harrington KE, et al. (2001) The efficacy and safety of nutritional supplement use in a representative sample of adults in the North/South Ireland Food Consumption Survey. Public Health Nutr 4, 1089-1097.

24. Central Statistics Office. (CSO) (2007) Census 2006: Principal Demographic Results. Dublin: The Stationery Office.

25. Harrington KE, Robson PJ, Kiely M, et al. (2001) The North/ South Ireland Food Consumption Survey: survey design and methodology. Public Health Nutr 4, 1037-1042.

26. Hill TR, O'Brien MM, Cashman KD, et al. (2004) Vitamin D intakes in 18-64-y-old Irish adults. Eur J Clin Nutr 58, 1509-1517.

27. Black LJ, Ireland J, Møller A, et al. (2011) Development of an on-line Irish food composition database for nutrients. J Food Compos Anal 24, 1017-1023.

28. Cashman KD, Hill TR, Cotter AA, et al. (2008) Low vitamin D status adversely affects bone health parameters in adolescents. Am J Clin Nutr 87, 1039-1044.

29. Holick MF, Binkley NC, Bischoff-Ferrari HA, et al. (2011) Evaluation, treatment, and prevention of vitamin D deficiency: an Endocrine Society clinical practice guideline. J Clin Endocrinol Metab 96, 1911-1930.

30. Diffey BL (2010) Modelling the seasonal variability of vitamin D due to sun exposure. Br J Dermatol 162, 1342-1348.

31. Hyppönen E \& Power C (2007) Hypovitaminosis D in British adults at age $45 \mathrm{y}$ : nationwide cohort study of dietary and lifestyle predictors. Am J Clin Nutr 85, 860-868.

32. Ruston D, Hoare J, Henderson L, et al. (2004) The National Diet and Nutrition Survey: Adults Aged 19-64 years. Volume 4: Nutritional Status (Anthropometry and Blood Analytes), Blood Pressure and Physical Activity. London: The Stationery Office.

33. Finch S, Doyle W, Lowe C, et al. (1998) National Diet and Nutrition Survey: People Aged 65 years and Over. Volume 1: Report of the Diet and Nutrition Survey. London: The Stationery Office.

34. Flynn A, Hirvonen T, Mensink GB, et al. (2009) Intake of selected nutrients from foods, from fortification and from supplements in various European countries. Food Nutr Res 12, 53

35. Gahche J, Bailey R, Burt V, et al. (2011) Dietary supplement use among U.S. adults has increased since NHANES III (1988-1994). NCHS Data Brief 61, 1-8.

36. Holick MF, Matsuoka LY \& Wortsman J (1989) Age, vitamin D, and solar ultraviolet. Lancet 2, 1104-1105.

37. Need AG, Morris HA, Horowitz M, et al. (1993) Effects of skin thickness, age, body fat, and sunlight on serum 25-hydroxyvitamin D. Am J Clin Nutr 58, 882-885.

38. Henderson L, Irving K, Gregory J, et al. (2004) The National Diet and Nutrition Survey: Adults Aged 19 to 64 years Vitamin and Mineral Intake and Urinary Analytes. London: TSO. 